\title{
Mindfulness-Related Variables and Sexual/Relationship Satisfaction in People with Physical Disabilities
}

\author{
Raquel Pereira ${ }^{1}$ (D) $\cdot$ Isabel Almeida ${ }^{2}$ (D) $\cdot$ Pedro M. Teixeira $^{3}$ (D) $\cdot$ Pedro J. Nobre $^{1}$ (D)
}

Published online: 5 June 2020

(C) Springer Science+Business Media, LLC, part of Springer Nature 2020

\begin{abstract}
Objectives Research has shown the role of mindfulness and self-compassion in promoting resilience while living with a disabling condition. However, little is known on the influence of these variables on sexual and relationship satisfaction of people with physical disabilities. This cross-sectional study aimed to explore the contribution of mindfulness, self-compassion, and acceptance in predicting sexual and relationship satisfaction, above and beyond experiencing physical disability.

Methods A sample of 377 participants, aged between 18 and 55 years old, took part in a survey. Of these, 189 participants had a self-reported physical disability, the majority $(70.1 \%)$ being either motor or neuromuscular health conditions.

Results Findings showed that higher levels of mindfulness, self-compassion, and acceptance significantly predicted higher sexual $\left(\Delta R^{2}=\right.$ between .081 and $\left..166 ; p<.05\right)$ and relationship satisfaction $\left(\Delta R^{2}=\right.$ between .072 and $\left..106 ; p<.05\right)$, above and beyond the physical condition of the participants. Additionally, the physical condition was a moderator for the relationship between the mindfulness dimension of self-compassion and sexual satisfaction $\left(\Delta R^{2}=.024 ; p=.037\right)$, as this association was only significant for people with physical disabilities.

Conclusions This study explores possible vulnerability and protective psychological mechanisms that may be involved in sexual and relationship satisfaction, above and beyond the effects of the physical disability. Despite its limitations, findings call into attention for the importance of further research on mindfulness-related variables in optimizing sexual health in people with and without physical disabilities.
\end{abstract}

Keywords Acceptance $\cdot$ Mindfulness $\cdot$ Physical disabilities $\cdot$ Relationship satisfaction $\cdot$ Self-compassion $\cdot$ Sexual satisfaction

The sexuality of people with physical disabilities is still frequently ignored and stigmatized by society, which may imply several challenges in developing sexually satisfying relationships (Esmail et al. 2010). However, while physical disability challenges human corporeality and functionality, it also has the potential to break normative standards of experiencing sexual and relationship satisfaction (Shakespeare 2006; Smith 2009; Swain and French 2008). Research has shown their role in facilitating resilience while living with a disabling

Raquel Pereira

arlpereira.rp@gmail.com

1 Faculty of Psychology and Educational Sciences, University of Porto, Rua Alfredo Allen, 4200-135 Porto, Portugal

2 Professional Rehabilitation Centre of Gaia, Arcozelo, Portugal

3 Life and Health Sciences Research Institute ICVS/3B's, PT Government Associate Laboratory, Braga/Guimarães, School of Medicine, University of Minho, Braga, Portugal condition (Kelland 2009; Stuntzner and Hartley 2015). Thus, examining variables such as mindfulness, self-compassion, and acceptance may clarify our understanding of the coping mechanisms involved in sexual health, specifically on sexual and relationship satisfaction, of people who may live with a physical disability.

Around $15 \%$ of the world population lives with some kind of disability (World Health Organization 2011). According to a biopsychosocial model of disability, physical disability can be defined as a condition where a person experiences significant deviation or loss in a body function or structure, with impact on their physical activity (World Health Organization 2001a). There are several physical conditions which can be acquired or congenital, i.e., motor impairments (e.g., paraplegia, tetraplegia, amputation), sensorial impairments (e.g., visual or hearing impairments), and neurological impairments (e.g., multiple sclerosis, cerebral palsy, muscular dystrophy) (Rowen et al. 2015). Thus, people with a physical disability may experience partial or total restrictions in daily activities that limit full participation in several domains of life, 
including sexual expression and sexual health (World Health Organization 2001a).

Sexual satisfaction is essential for sexual health and overall well-being (World Health Organization 2006). Sexual satisfaction is described as "an affective response arising from one's subjective evaluation of the positive and negative dimensions associated with one's sexual relationship" (Lawrance and Byers 1995). Sexual satisfaction is usually regarded as an intrapersonal variable, but more comprehensive research indicated that relational or dyadic sexual rewards are often linked to people's appraisal of sexual satisfaction (McClelland 2014; Pascoal et al. 2014). Therefore, it is also important to evaluate relationship satisfaction, since research reports the benefits of sexual communication for overall sexual and relationship satisfaction (Sánchez-fuentes et al. 2014). Regarding physical disability, the literature is heterogeneous; but frequently, studies point out a decrease in sexual satisfaction after acquiring a disabling condition (McCabe and Taleporos 2003; Taleporos and McCabe 2003). Also, previous research found that higher levels of satisfaction (with sexual life, health, social lives) were associated with relationships formed after the impairment (Crewe and Krause 1988; Taleporos and McCabe 2003). Moreover, the lack of sexual satisfaction seems to be the strongest predictor for seeking professional help in people with disabilities and chronic diseases, emphasizing its relevance for sexual health (Kedde et al. 2012).

There is evidence of several issues that may contribute to explaining sexual health, particularly sexual and relationship satisfaction, of people with disabilities that go beyond the effects of the impairment, i.e., socio-sexual isolation (due to architectural or economic restrictions), family overprotection and lack of privacy, bodily perfection ideals, lack of sex education, internalization of normative models, and lack of awareness and empowerment (Ahumuza et al. 2014; García and Álvarez 2014). These factors entail not only a structural disablism - the social oppression of the sexual expression of people with physical disabilities - but also the psychoemotional disablism, which leads to a process of internalized oppression. Internalized oppression pertains to the internalization of stigma and prejudices by a certain marginalized group about themselves, which shapes thoughts, emotions, and actions, affecting their self-esteem and mental health (Reeve 2004). Therefore, psychological factors such as mindfulness, self-compassion, and acceptance may apply to the understanding of the internalized processes that impact on the sexual health of people with physical disabilities (Lucena-Santos et al. 2015). By developing awareness of the context and function of thoughts and emotions, these approaches evolved from the cognitive-behavioral models, and entail a more holistic and flexible view of human experience (Hayes 2004). More than the potential benefits of these strategies for sexual health, they promote self-empowerment and self- determination, which may lead to sexual rights advocacy (Stuntzner and Hartley 2015).

Mindfulness is defined as "awareness that arises through paying attention, on purpose, in the present moment, nonjudgmentally" (Kabat-Zinn and Burney 1981). Thus, mindfulness can be conceptualized as a dispositional or trait-like characteristic, a set of skills or a state of awareness (Baer 2003). Mindfulness has been commonly applied in the fields of chronic disease and sex therapy (Baer 2003; Brotto et al. 2015; Brotto and Heiman 2007; Johnston 2012; Kocsis and Newbury-Helps 2016). Regarding disability, mindfulness has been applied to patients with multiple sclerosis, and research has largely shown its role in increasing quality of life, emotional regulation, and resilience (Senders et al. 2012). A study has analyzed the adequacy of mindfulness-based programs to different conditions, and confirmed the participants' adherence and motivation towards the practices (Goodrich et al. 2015). Concerning sexual health, recent research has documented the benefits of a psychoeducational group approach that includes mindfulness in improving the sexual adjustment of women with multiple sclerosis and spinal cord injury (Hocaloski et al. 2016). Nevertheless, a different study with women with multiple sclerosis indicated that patients who performed the combined therapies (i.e., mindfulness and pelvic floor exercises) did not experience additional benefits on sexual functioning when compared with those who performed either mindfulness or pelvic floor exercises (equally beneficial) (Mosalanejad et al. 2018).

Self-compassion integrates mindfulness' rationale and techniques, but goes beyond the notion of the present moment experience (Neff and Dahm 2015). This construct pertains to the capacity to be open to one's suffering and has three components, i.e., self-kindness (i.e., being warm and understanding toward ourselves when we suffer, fail, or feel inadequate), common humanity (i.e., recognizing that suffering and personal inadequacy is part of the shared human experience), and mindfulness (i.e., being receptive and non-judgmental of one's thoughts and feelings, particularly of those related to the painful experience) (Neff 2003a; Neff and Dahm 2015). Similarly to mindfulness, self-compassion can be conceptualized as a modifiable trait-like dimension and a developmental skill (Neff and Dahm 2015). Self-compassion has been established as an important aspect of resilience and self-empowerment, and interventions based on self-compassion have proven effective at follow-up moments (Germer and Neff 2013; Neff and Germer 2013; Stuntzner and Hartley 2015). For example, a study with 19 adults with spina bifida found positive and significant correlations between participants' resilience, self-esteem, and self-compassion (Hayter and Dorstyn 2014). Additionally, interventions aimed at increasing self-compassion combined with mindfulness have shown decreased functional disability in war veterans (Dahm et al. 2015). Regardless of the lack of research on self-compassion 
applied to sexuality, there is literature discussing the potential benefits of teaching women with disabilities how to be selfcompassionate when coping with their sexual issues and improving their sexual identity (Stuntzer 2014).

Finally, acceptance and commitment therapeutic approaches emphasize the concept of acceptance as a capacity to act towards one's goals with a non-judgmental attitude and taking into account values (Hayes et al. 1999). This capacity highlights the psychological (in)flexibility or experiential avoidance in the face of negative events (Hayes et al. 1999). There is broad evidence of the efficacy of acceptance approaches on health issues, mainly on pain conditions, with improvements in physical and social functioning (McCracken and Vowles 2014). However, literature is scarce in establishing the link between acceptance and sexuality, but a study from Nezhad and Shameli (2017) showed that acceptance and commitment therapy is effective in increasing sexual satisfaction in couples.

In sum, the understanding of sexual and relationship satisfaction in people with physical disabilities seems complex, as disability is multifactorial (World Health Organization 2001a). Thus, the sexual expression of people with physical disabilities is susceptible to the influence of barriers and facilitators, namely of psychological dimensions. Variables such as mindfulness, self-compassion, and acceptance have already been established in the literature as important mechanisms in dealing with health issues and disablism (Brown and Ryan 2003; McCracken and Vowles 2014; Stuntzner et al. 2018). Evidence on the role of these factors for sexual health, namely sexual and relationship satisfaction, of people who may experience physical disability is much needed.

This study is part of a larger mixed-methods research project that aims to contribute to the understanding of the role of psychological factors in influencing the sexual health of people with physical disabilities. Using a cross-sectional design, the current study explored the relationships between mindfulness, self-compassion, acceptance, and sexual health variables (i.e., sexual and relationship satisfaction) in a sample that includes people with physical disabilities. Specifically, we aimed to analyze the contribution of mindfulness, self-compassion, and acceptance in predicting the variability of sexual and relationship satisfaction of men and women above and beyond their physical condition. Based on the literature, we expected that, after controlling for physical condition (i.e., having a physical disability or not), higher levels of mindfulness, self-compassion, and acceptance would predict (i) higher sexual satisfaction and (ii) higher relationship satisfaction. Furthermore, we examined possible moderating effects of physical condition or gender on the relationship between third wave cognitive-behavioral variables and sexual health variables (i.e., sexual and relationship satisfaction).

\section{Methods}

\section{Participants}

Study participants were recruited according to the following inclusion criteria: (i) being aged between 18 and 55 years old; (ii) having a physical disability or no disability; (iii) being able to read Portuguese and provide informed consent. Regarding physical disability criteria, we included people with different health conditions, from the motor and neuromuscular impairments to sensory impairments, in order to diversify our sample accounting for the psychosocial dimensions of disability, namely the stigma regarding their sexuality. Nonetheless, participants with moderate to severe cognitive impairments were excluded, since they are often incapable of providing informed consent. Also, participants older than 55 years were excluded, as age is often a variable that has a negative impact over sexual functioning.

Initially, 479 individuals participated in the survey. Participants were included in the study if they fulfilled all the sociodemographic, medical, and disability details, and at least one of the psychological measures. Due to an overrepresentation of able-bodied women $(n=198), 96$ of them were randomly selected and matched with the other participants. The final sample consisted of 377 participants $(58.6 \%$ completed all the measures). Of these, 189 had a physical disability (96 men and 93 women) and 188 had no disability (92 men and 96 women).

Mean age of the participants was 32.80 years $(\mathrm{SD}=9.5)$, being that people with physical disabilities were older $(\mathrm{M}=$ $36.54 ; \mathrm{SD}=9.43)$ than people without disabilities $(\mathrm{M}=29.12$; $\mathrm{SD}=8.11)$. A significant percentage of the sample $(42.1 \%)$ had, at least 12 years of education, and most were either employed (38\%) or studying (29.2\%). Regarding marital status, although most participants reported being single (66.5\%), $64.5 \%$ of the sample was in a relationship for an average of 7 years. Most participants were heterosexual (77.4\%), and $38.5 \%$ of the sample reported self-perceived sexual difficulties in the past 6 months. For men, the most common sexual problems related to erectile difficulties (21.4\%), lack of sexual desire (19.4\%), and delayed ejaculation (16.7\%). For women, lack of sexual desire was the most frequent sexual difficulty (27.8\%). Table 1 displays participants' sociodemographic and sexual health characteristics, regarding their gender and physical condition.

Of the 189 participants with physical disabilities, most of them had an acquired disability (62.8\%) for 12 years on average, and most of the conditions were caused by disease $(62.2 \%)$. The most frequent kinds of disability were neuromuscular conditions (e.g., multiple sclerosis, acquired brain injuries, 37.3\%) and motor impairments (e.g., spinal cord injuries, amputations, $32.8 \%$ ). A percentage of $23.2 \%$ reported other kinds of disabling health conditions, such as chronic 
Table 1 Participants' sociodemographic, sexual health, and disability characteristics $(N=377)$

\begin{tabular}{|c|c|c|c|c|c|c|c|c|}
\hline & \multicolumn{2}{|c|}{$\begin{array}{l}\text { Men with } \\
\text { physical } \\
\text { disabilities } \\
(n=96)\end{array}$} & \multicolumn{2}{|c|}{$\begin{array}{l}\text { Women } \\
\text { with } \\
\text { physical } \\
\text { disabilities } \\
(n=93)\end{array}$} & \multicolumn{2}{|c|}{$\begin{array}{l}\text { Men } \\
\text { without } \\
\text { physical } \\
\text { disabilities } \\
(n=92)\end{array}$} & \multicolumn{2}{|c|}{$\begin{array}{l}\text { Women } \\
\text { without } \\
\text { physical } \\
\text { disabilities } \\
(n=96)\end{array}$} \\
\hline \multicolumn{9}{|l|}{ Age } \\
\hline $\begin{array}{l}\text { M } \\
\text { Range } \\
\text { SD }\end{array}$ & \multicolumn{2}{|c|}{$\begin{array}{l}35.43 \\
18-54 \\
9.57\end{array}$} & \multicolumn{2}{|c|}{$\begin{array}{l}37.64 \\
19-55 \\
9.2\end{array}$} & \multicolumn{2}{|c|}{$\begin{array}{l}30.18 \\
18-50 \\
8.31\end{array}$} & \multicolumn{2}{|c|}{$\begin{array}{l}28.09 \\
18-48 \\
7.82\end{array}$} \\
\hline & $N$ & $\%$ & $N$ & $\%$ & $N$ & $\%$ & $N$ & $\%$ \\
\hline \multicolumn{9}{|l|}{ Marital status } \\
\hline $\begin{array}{l}\text { Married/CL } \\
\text { Single } \\
\text { Divorced }\end{array}$ & $\begin{array}{l}27 \\
55 \\
8\end{array}$ & $\begin{array}{l}30 \\
61.1 \\
8.9\end{array}$ & $\begin{array}{l}39 \\
51 \\
9\end{array}$ & $\begin{array}{l}32.6 \\
57.3 \\
10.1\end{array}$ & $\begin{array}{l}19 \\
65 \\
4\end{array}$ & $\begin{array}{l}21.6 \\
73.9 \\
4.5\end{array}$ & $\begin{array}{l}29 \\
51 \\
9\end{array}$ & $\begin{array}{l}32.6 \\
57.3 \\
10.1\end{array}$ \\
\hline \multicolumn{9}{|l|}{ Educational level } \\
\hline $\begin{array}{l}0-4 \text { years } \\
5-6 \text { years } \\
7-9 \text { years } \\
10-12 \text { years } \\
13-15 \text { years } \\
+15 \text { years }\end{array}$ & $\begin{array}{l}1 \\
17 \\
13 \\
34 \\
16 \\
8\end{array}$ & $\begin{array}{l}1.1 \\
19.1 \\
14.6 \\
38.2 \\
18 \\
9\end{array}$ & $\begin{array}{l}3 \\
4 \\
8 \\
31 \\
32 \\
6\end{array}$ & $\begin{array}{l}3.6 \\
4.8 \\
9.5 \\
36.9 \\
38.1 \\
7.2\end{array}$ & $\begin{array}{l}- \\
- \\
1 \\
17 \\
32 \\
34\end{array}$ & $\begin{array}{l}- \\
- \\
1.2 \\
20.2 \\
38.1 \\
40.4\end{array}$ & $\begin{array}{l}- \\
- \\
1 \\
16 \\
40 \\
33\end{array}$ & $\begin{array}{l}- \\
- \\
1.1 \\
17.8 \\
44.4 \\
36.6\end{array}$ \\
\hline \multicolumn{9}{|c|}{ Self-perceived sexual problems } \\
\hline $\begin{array}{l}\text { With sexual } \\
\text { problems } \\
\text { Without sexual } \\
\text { problems } \\
\text { Onset of disability }\end{array}$ & $\begin{array}{l}38 \\
57\end{array}$ & $\begin{array}{l}40 \\
60\end{array}$ & $\begin{array}{l}33 \\
58\end{array}$ & $\begin{array}{l}36.3 \\
63.7\end{array}$ & $\begin{array}{l}35 \\
57\end{array}$ & $\begin{array}{l}38 \\
62\end{array}$ & $\begin{array}{l}38 \\
58\end{array}$ & $\begin{array}{l}39.6 \\
60.4\end{array}$ \\
\hline $\begin{array}{l}\text { Congenital } \\
\text { Acquired }\end{array}$ & $\begin{array}{l}25 \\
48\end{array}$ & $\begin{array}{l}34.2 \\
65.8\end{array}$ & $\begin{array}{l}26 \\
38\end{array}$ & $\begin{array}{l}40.6 \\
59.4\end{array}$ & $\begin{array}{l}- \\
-\end{array}$ & - & - & - \\
\hline \multicolumn{9}{|l|}{ Kind of disability } \\
\hline $\begin{array}{l}\text { Motor } \\
\text { Neuromuscular } \\
\text { Sensorial } \\
\text { Other* }\end{array}$ & $\begin{array}{l}29 \\
41 \\
4 \\
18\end{array}$ & $\begin{array}{l}31.5 \\
44.6 \\
4.3 \\
19.6\end{array}$ & $\begin{array}{l}29 \\
25 \\
8 \\
23\end{array}$ & $\begin{array}{l}34.1 \\
29.4 \\
9.4 \\
27.1\end{array}$ & $\begin{array}{l}- \\
- \\
- \\
-\end{array}$ & $\begin{array}{l}- \\
- \\
-\end{array}$ & $\begin{array}{l}- \\
- \\
- \\
-\end{array}$ & $\begin{array}{l}- \\
- \\
- \\
-\end{array}$ \\
\hline \multicolumn{9}{|l|}{ Cause of disability } \\
\hline $\begin{array}{l}\text { Accident } \\
\text { Disease } \\
\text { Other** }\end{array}$ & $\begin{array}{l}26 \\
30 \\
2\end{array}$ & $\begin{array}{l}44.8 \\
51.7 \\
3.4\end{array}$ & $\begin{array}{l}12 \\
39 \\
2\end{array}$ & $\begin{array}{l}22.6 \\
73.6 \\
3.8\end{array}$ & $\begin{array}{l}- \\
- \\
-\end{array}$ & $\begin{array}{l}- \\
- \\
-\end{array}$ & $\begin{array}{l}- \\
- \\
-\end{array}$ & $\begin{array}{l}- \\
- \\
-\end{array}$ \\
\hline
\end{tabular}

$C L$, common law

*Conditions such as cancer, chronic pain, and fibromyalgia

**E.g., birth complications

pain and cancer, and only $9.4 \%$ reported sensory impairments (e.g., blindness and deafness) (see Table 1 for more details regarding gender). Most of these participants required aid products for mobility, such as crutches $(23.4 \%)$, manual wheelchair $(23.4 \%)$, or electric wheelchair $(15.2 \%)$. Nevertheless, $75.5 \%$ of the subsample revealed full autonomy in daily life activities (e.g., eating, dressing, taking a bath).

\section{Procedure}

Study participants took part in a survey about psychological, sexual, and relationship information, as well as sociodemographic and disability-related data. Participants answered either a male or female version of the questionnaires, which could be fulfilled online or in paper format, allowing the volunteers to access inclusive methods of participation and reach a wider population. Most participants took the online format $(85.9 \%)$, managed with the Limesurvey template (https://www.limesurvey.org) stored in a server from the University of Porto. Nevertheless, 51 paper questionnaires were registered, as well as 2 questionnaires answered by telephone. Also, a pilot study was conducted with volunteers, using both online and paper formats, to test the adequacy and clarity of the language and instructions, to identify possible technical errors, and to estimate the total response time (approximately $30 \mathrm{~min}$ ).

The study was publicized on several social networks and mailing lists (e.g., Facebook, including institutional pages of the research team and the faculty; LinkedIn; institutional mailing lists), blogs and websites dedicated to sexuality and disability, and on electronic newspapers. Participants were also recruited from a professional rehabilitation facility in a city in the North of Portugal. At the beginning of the survey, participants received a full explanation of the purpose of the study, accounting for the inclusion criteria. After giving their informed consent, they would be able to complete the survey's questions. To guarantee the participants' anonymity and confidentiality, no personal data (e.g., name, birthday) were asked. Also, the first author provided an electronic mail address to participants, in case they had any questions related to the study. Although their participation was voluntary, participants would be entitled to enroll in a prize draw and win $20 €$, as an incentive for taking the survey. The sample was collected between March 2017 and July 2018.

\section{Measures}

\section{Descriptive Variables}

Participants completed a self-report introductory questionnaire that assesses several sociodemographic, relational, and sexual questions (e.g., age, education level, occupation, residence area, marital and relationship status, self-identified sexual orientation, sexual health, and behavior). This questionnaire also addresses medical history (including questions about medication) and disability (including type, cause, and severity of disability), with questions adapted from the Lifestyle and Medical History Questionnaire and the Disability Assessment Schedule (World Health Organization 2001b). Furthermore, this questionnaire also examined selfperceived sexual difficulties, using dichotomous questions (i.e., "Yes/No" questions) adapted from Peixoto and Nobre (2015a, 2015b), which considers perceived distress. 


\section{Mindfulness}

The capacity to be self-conscious and oriented to the present moment was measured through the Five Facets of Mindfulness Questionnaire (FFMQ; Baer et al. 2006; Gregório and Pinto-Gouveia 2011). This is a 39-item measure adapted from previous scales and has five factors as follows: observe (e.g., "When I take a shower or bath, I stay alert to the sensations of water on my body"), describe (e.g., "It's hard for me to find words to describe what I'm thinking"), act with awareness (e.g., "I find it difficult to stay focused on what's happening in the present"), non-judge (e.g., "I tell myself I shouldn't be feeling the way I'm feeling"), and non-react (e.g., "I perceive my feelings and emotions without having to react to them") (Baer et al. 2006). Participants answer in a 5-point Likert scale that ranges between 1 ("never or very rarely true") and 5 ("very often or always true"). Scores vary between 8 and 40 points, except for the non-react dimension, which ranges between 7 and 35 points. Higher scores mean overall higher mindfulness qualities. Psychometric studies revealed good internal consistency for each factor ( $\alpha$ of Cronbach between 0.75 and 0.91 ), as well as good convergent and discriminant validity (Baer et al. 2006). The Portuguese version also showed good internal consistency ( $\alpha$ of Cronbach between 0.72 and 0.93 ), and structural invariance of the scale was proved for the Portuguese population (Gregório and PintoGouveia 2011). In the current study, the scale showed good internal consistency overall $(\alpha=0.84)$ and for each dimension ( $\alpha$ between 0.77 and 0.90 ). Focusing on the subsamples, the scale showed good internal consistency for both people with physical disabilities ( $\alpha=0.84$; subscales between 0.74 and 0.90 ) and people without physical disabilities ( $\alpha=0.88$; subscales between 0.81 and 0.91). Moreover, small language changes were implemented to avoid discriminating participants with mobility issues (e.g., "When I'm moving..." instead of "When I'm walking...").

\section{Self-Compassion}

The Self-Compassion Scale (SCS) was administered to measure the individuals' capacity to bear one's feelings of suffering using a sense of warmth, connection, and concern (Castilho and Pinto-Gouveia 2011; Neff 2003b). This is a 26-item self-report scale subdivided into 6 factors as follows: self-kindness (e.g., "When I'm going through a very hard time, I give myself the caring and tenderness I need"), selfjudgment (e.g., "I'm disapproving and judgmental about my own flaws and inadequacies"), common humanity (e.g., "I try to see my failings as part of the human condition"), isolation (e.g., "When I fail at something that is important to me, I tend to feel alone in my failure"), mindfulness (e.g., "When something upsets me I try to keep my emotions in balance"), and over-identification (e.g., "When I fail at something important to me I become consumed by feelings of inadequacy") (Neff 2003b). Answers are rated on a 5-point Likert scale that ranges between 1 ("almost never") and 5 ("almost always"), and subscale scores may vary between 4 and 20, except for selfkindness and self-judgment (between 5 and 25). Items from self-judgment, isolation, and over-identification subscales should be reversed for the computation of a total score. Thus, higher values are equal to higher self-compassion. Initial psychometric studies revealed good internal consistency $(\alpha=0.92)$ and good test-retest validity $(\alpha=0.93)$ of the scale (Neff 2003b). The Portuguese version of the scale also demonstrated good internal consistency for all 26 items $(\alpha=$ 0.89 ) and for each dimension ( $\alpha$ between 0.73 and 0.84 ), as well as good convergent and discriminant validity and testretest reliability (Castilho and Pinto-Gouveia 2011). In the current study, the scale showed good internal consistency overall $(\alpha=0.92)$ and for each of the six original dimensions ( $\alpha$ between 0.72 and 0.82 ). Focusing on the subsamples, the scale showed good internal consistency for both people with physical disabilities ( $\alpha=0.91$; subscales between 0.63 and 0.81 ) and people without physical disabilities ( $\alpha=0.93$; subscales between 0.74 and 0.87 ).

\section{Acceptance}

The second version of the Acceptance and Action Questionnaire (AAQ-II) was used to examine participants' psychological inflexibility or experiential avoidance in the face of negative events (Bond et al. 2011; Pinto-Gouveia et al. 2012). This is a 7-item self-report questionnaire that is rated according to a 7-point Likert-type scale, ranging between 1 ("never true") and 7 ("always true"). This scale has a one-factor structure with higher scores indicating greater psychological inflexibility or experiential avoidance (Bond et al. 2011). Psychometric studies showed good internal consistency across six samples (mean $\alpha=0.84$ ) and good testretest validity ( $\alpha=0.81$ at 3 months; $\alpha=0.79$ at 12 months) (Bond et al. 2011). The Portuguese version also identified a one-factor model and showed good internal consistency $(\alpha=$ 0.90 ), as well as convergent and discriminant validity (PintoGouveia et al. 2012). In the current study, the scale showed good internal consistency $(\alpha=0.92)$. Focusing on the subsamples, the scale showed good internal consistency for both people with physical disabilities $(\alpha=0.92)$ and people without physical disabilities $(\alpha=0.91)$.

\section{Sexual Satisfaction}

The Global Measure of Sexual Satisfaction (GMSEX) was administered to evaluate the satisfaction with sexual activity in relationships (Lawrance and Byers 1992; Pascoal et al. 2013). It is a 5-item self-reported questionnaire which assesses the qualities of the sexual dimension of relationships 
according to a 7-point Likert scale that ranges in a spectrum between 1 (the positive side) and 7 (the negative side). Lower total scores represent higher levels of sexual satisfaction. Psychometric studies showed good internal consistency of the measure $(\alpha=0.90)$, good time stability ( $r$ Pearson between 0.84 and 0.78$)$, and good convergent validity $(r=0.70)$ (Lawrance and Byers 1992). The Portuguese version revealed good internal consistency ( $\alpha=0.96$ ) (Pascoal et al. 2013). In this study, the scale showed good internal consistency for the whole sample $(\alpha=0.95)$. Focusing on the subsamples, the scale showed good internal consistency for both people with physical disabilities $(\alpha=0.96)$ and people without physical disabilities $(\alpha=0.94)$.

\section{Relationship Satisfaction}

The Global Measure of Relationship Satisfaction (GMREL) was used to analyze how satisfied were the participants with their relationships overall (Lawrance and Byers 1992; Pascoal et al. 2015). This 5-item self-report questionnaire assesses relationship qualities according to 7-point Likert-type scales ranging in a spectrum between 1 (the positive side) and 7 (the negative side). Lower total scores indicate higher relationship satisfaction. Psychometric studies revealed good validity and feasibility of the questionnaire (Lawrance and Byers 1992). Further analyses showed good internal consistency ( $\alpha$ ranging between 0.95 and 0.96) (Lawrance and Byers 1992). The adaptation and validation of the scale in three different samples of the Portuguese population also showed good validity and consistency ( $\alpha$ ranging between 0.95 and 0.96 ) (Pascoal et al. 2015 ). In this study, the scale showed good internal consistency for the whole sample $(\alpha=0.97)$. Focusing on the subsamples, the scale showed good internal consistency for both people with physical disabilities $(\alpha=0.97)$ and people without physical disabilities $(\alpha=0.97)$.

\section{Data Analyses}

Statistical analysis was performed using the Statistical Package for Social Sciences software (SPSS version 25.0; Chicago, Inc, IL). Missing values were not treated (i.e., questionnaires with missing values were not analyzed). Descriptive characteristics of the sample were analyzed with percentages, means, and standard deviations. Study variables were also described with means and standard deviations, and were analyzed with bivariate correlations. Before conducting inferential analyses, participant's scores on the study variables were transformed into $z$-scores with a mean of 0 and a standard deviation of 1 .

To examine the potential contribution of third wave cognitive-behavioral variables to the sexual and relationship satisfaction, several hierarchical multiple regression analyses were computed. As there were significant statistical differences between participants with and without disabilities regarding age $\left(F_{1,369}=66.046, p<.001\right)$, this variable was used as a control variable and was entered in the first step of the models. Physical condition (i.e., having a physical disability or not) was then entered in the second step of the models. In the third step, one of the following variables was entered, i.e., (i) participants' scores of the five facets of mindfulnessobserve, describe, act with awareness, non-judge, and nonreact; (ii) participants' scores of the six factors of self-compassion-self-kindness, self-judgment (reversed), common humanity, isolation (reversed), mindfulness, and overidentification (reversed); (iii) participants' total score of acceptance (AAQ-II). Then, the total scores of sexual and relationship satisfaction (GMSEX and GMREL) were used as criterion variables individually.

To examine the moderating effects of physical condition and gender on the relationship between third wave cognitivebehavioral variables and sexual health variables (i.e., sexual and relationship satisfaction), moderation analyses were conducted using the PROCESS v. 3.0 for SPSS (Hayes 2012). After selecting model 1 of the application, physical condition and gender were entered individually as dichotomous moderators. For each analysis, the scores of the five facets of mindfulness, the six factors of self-compassion, and the total score of acceptance were entered as independent variables separately. Accordingly, the scores of the sexual and relationship satisfaction (GMSEX and GMREL) were entered, one at a time, as dependent variables. The regression's simple slope graphics were analyzed as a moderating post hoc probing technique.

Preliminary analyses were conducted to ensure all the assumptions of regression analyses, namely, normality, linearity, multicollinearity, and homoscedasticity. Finally, for all of the analyses, two-sided tests were used, and a $p$ value less than .05 was considered statistically significant.

\section{Results}

Means and standard deviations of study variables (accounting for the total scores), as well as bivariate correlations ( $r$ Pearson), are displayed in Table 2. Several significant associations were found between these variables, namely between independent and criterion variables. There were significant negative associations between the five facets of mindfulness and the criterion variables, except for the observe facet and sexual $(r=-.068 ; p>.05)$ and relationship satisfaction $(r=-$ $.607 ; p>.05)$, for the non-judge facet and relationship satisfaction $(r=-0.130 ; p>.05)$, and for the non-react facet and sexual $(r=-.004 ; p>.05)$ and relationship satisfaction $(r=$ $.012 ; p>.05)$. Also, all six dimensions of self-compassion were negatively associated with the criterion variables, except for the self-kindness dimension $(r=-.141$ and $-.108 ; p>$ 





$.05)$. Higher levels of acceptance were significantly associated with higher sexual satisfaction $(r=.390 ; p<.01)$ and relationship satisfaction $(r=.365 ; p<.01)$. Finally, sexual and relationship satisfaction correlated significantly with physical condition $(r=-.155$ and $-.237 ; p<.01)$, but not with age $(r=-.029$ and $.124 ; p>.05)$.

\section{Associations Between Sexual and Relationship Satisfaction and Mindfulness}

To assess the relationship between sexual satisfaction and mindfulness, age was entered in the first step of the model, which did not explain a significant amount of variance of sexual satisfaction $\left(R^{2}=.003 F_{1,155}=0.422, p=.517 ; \Delta R^{2}\right.$ $=.003)$. Also, the inclusion of physical condition at step $2 \mathrm{did}$ not explain a significant amount of the variance of the model $\left(\Delta R^{2}=.022 ; R^{2}=.024 ; F_{1,154}=3.422, p=.066\right)$. After including the five facets of mindfulness at step 3 , the final model was significant and the number of added variables explained an additional $8.1 \%$ of variance $\left(\Delta R^{2}=.081 ; R^{2}=\right.$ $.106 ; F_{5,149}=2.710, p=.022$ ). Specifically, higher levels of acting with awareness were significantly associated with higher sexual satisfaction, regardless of age and physical condition ( $\beta=-0.174, p=.054)$ (see Table 3).

Furthermore, several hierarchical multiple regressions were conducted with the assistance of the PROCESS to test potential moderation effects of physical condition and gender. Nevertheless, no moderating effects were found for the interaction terms between physical condition and the mindfulness facets, or between gender and the mindfulness facets.

To examine the association between relationship satisfaction and mindfulness, age was entered in the first step of the hierarchical multiple regression, which did not explain a significant amount of the variance of relationship satisfaction $\left(R^{2}=.019 ; F_{1,158}=3.085, p=\right.$ $\left..081 ; \Delta R^{2}=0.019\right)$. At step 2 , with the inclusion of physical condition, the model was significant and explained an additional $2.3 \%$ of the variance $\left(\Delta R^{2}=\right.$ $\left..023 ; R^{2}=.042 ; F_{1,157}=3.790, p=.053\right)$. The inclusion of the five facets of mindfulness at step 3 explained an additional $7.2 \%$ of the variance of the model $\left(\Delta R^{2}=.072 ; R^{2}=.114 ; F_{5,152}=2.472, p=.035\right)$. Specifically, higher levels of acting with awareness were significantly associated with higher relationship satisfaction, regardless of the fact of having a physical disability and after controlling for age $(\beta=-0.196, p$ $=.019)($ see Table 3$)$. Moreover, several hierarchical multiple regressions were conducted with the assistance of the PROCESS to test potential moderation effects of physical condition and gender. However, no moderating effects were found for the interaction terms between physical condition and any of the mindfulness facets, or between gender and any of the mindfulness facets.

\section{Associations Between Sexual and Relationship Satisfaction and Self-compassion}

To analyze the relationship between sexual satisfaction and different dimensions of self-compassion, age was entered in the first step of the hierarchical multiple regression, which did not explain a significant amount of the variance $\left(R^{2}=.015 ; F_{1,165}=2.587, p=.110 ; \Delta R^{2}=\right.$ $.015)$. At step 2 , the model was significant, and the inclusion of physical condition explained an additional $4.7 \%$ of the variance of sexual satisfaction $\left(\Delta R^{2}=.047 ; R^{2}=.062\right.$; $\left.F_{1,164}=8.193, p=.005\right)$. The addition of the six dimensions of self-compassion at step 3 explained an additional $8.5 \%$ of the variance of the model $\left(\Delta R^{2}=.085 ; R^{2}=\right.$ $\left..148 ; F_{5,158}=2.634, p=.018\right)$. However, there were no specific dimensions that significantly associated with sexual satisfaction, above and beyond the fact of having a physical disability and after controlling for age (see Table 4).

Furthermore, several hierarchical multiple regressions were conducted with the assistance of the PROCESS to test potential moderation effects of physical condition and gender. Results showed a moderating effect for the interaction term between physical condition and the mindfulness dimension $(\beta$ $=0.159, \mathrm{t}_{187}=2.09, p=.037 ; R^{2}=.123 ; F_{3,187}=5.42, p=$ $.001)$, which accounted for $2.4 \%$ of the variance of sexual satisfaction $\left(\Delta R^{2}=.024 ; p=.037\right)$. As depicted in Fig. 1, the association between the mindfulness dimension and sexual satisfaction was negative for people with physical disabilities, while for able-bodied people, it was slightly positive and practically non-existent.

To assess the association between relationship satisfaction and different dimensions of self-compassion, age was entered in the first step of the hierarchical multiple regression, which explained $3 \%$ of the variance of relationship satisfaction $\left(R^{2}=.030 ; F_{1,167}=5.104, p=.025 ; \Delta R^{2}=\right.$ $.030)$. At step 2 , the inclusion of physical condition explained an additional $4.3 \%$ of the variance of the model $\left(\Delta R^{2}=.043, R^{2}=.073 ; F_{1,166}=7.776, p=.006\right)$. The insertion of the six dimensions of self-compassion at step 3 explained an additional $10.1 \%$ of the variance of the model $\left(\Delta R^{2}=.101, R^{2}=.174 ; F_{6,160}=3.272, p=\right.$ $.005)$. However, there were no specific dimensions that significantly associated with relationship satisfaction, above and beyond the fact of having a physical disability and after controlling for age (see Table 4). Several hierarchical multiple regressions were conducted with the assistance of the PROCESS to test potential moderation effects of physical condition and gender. Nevertheless, no moderating effects were found for the interaction terms between physical condition and any of the selfcompassion dimensions, or between gender and any of the self-compassion dimensions. 
Table 3 Hierarchical linear regression analyses of the five facets of mindfulness as predictors of sexual $(n=157)$ and relationship satisfaction $(n=160)$ in the total sample $(N=377)$

\begin{tabular}{|c|c|c|c|c|c|c|}
\hline Variable & $B$ & $\operatorname{SE} B$ & $\beta$ & $t$ & $R^{2}$ & $\Delta R^{2}$ \\
\hline \multicolumn{7}{|l|}{ GMSEX } \\
\hline Step 1 & & & & & .003 & .003 \\
\hline Age & 0.053 & 0.081 & 0.052 & 0.49 & & \\
\hline Step 2 & & & & & .024 & .022 \\
\hline Age & -0.005 & 0.086 & -0.005 & -0.054 & & \\
\hline Physical condition & -0.148 & 0.080 & -0.158 & -1.85 & & \\
\hline Step 3 & & & & & .106 & .081 \\
\hline Age & 0.036 & 0.087 & 0.035 & 0.412 & & \\
\hline Physical condition & -0.148 & 0.081 & -0.158 & -1.83 & & \\
\hline FFMQ observe & -0.132 & 0.083 & -0.134 & -1.58 & & \\
\hline FFMQ describe & -0.074 & 0.090 & -0.071 & -0.816 & & \\
\hline FFMQ act with awareness & -0.174 & 0.090 & -0.167 & $-1.94 *$ & & \\
\hline FFMQ non-judge & -0.127 & 0.089 & -0.124 & -1.41 & & \\
\hline FMQ non-react & 0.015 & 0.085 & 0.016 & 0.179 & & \\
\hline \multicolumn{7}{|l|}{ GMREL } \\
\hline Step 1 & & & & & .019 & .019 \\
\hline Age & 0.135 & 0.077 & 0.138 & 1.75 & & \\
\hline Step 2 & & & & & .042 & .023 \\
\hline Age & 0.084 & 0.081 & 0.086 & 1.03 & & \\
\hline Physical condition & -0.148 & 0.076 & -0.161 & $-1.94 *$ & & \\
\hline Step 3 & & & & & .114 & .072 \\
\hline Age & 0.111 & 0.081 & 0.114 & 1.38 & & \\
\hline Physical condition & -0.151 & 0.076 & -0.164 & $-1.97 *$ & & \\
\hline FFMQ observe & -0.111 & 0.080 & -0.116 & -1.38 & & \\
\hline FFMQ describe & -0.085 & 0.087 & -0.084 & -0.977 & & \\
\hline FFMQ act with awareness & -0.196 & 0.083 & -0.196 & $-2.36^{*}$ & & \\
\hline FFMQ non-judge & -0.061 & 0.083 & -0.061 & -0.727 & & \\
\hline FFMQ non-react & 0.062 & 0.082 & 0.064 & 0.754 & & \\
\hline
\end{tabular}

$* p<0.05 ; * * p<0.01 ; * * * p<0.001$

Final $n$ of the analyses range from 157 to 160 due to occasional missing data. All variables were computed into $z$ scores

GMSEX, total score Global Measure of Sexual Satisfaction; GMREL, total score of Global Measure of Relationship Satisfaction; FFMS observe, observe dimension of the Five Facets Mindfulness Questionnaire; FFMS describe, describe dimension of the Five Facets Mindfulness Questionnaire; FFMS act with awareness, act with awareness dimension of the Five Facets Mindfulness Questionnaire; FFMS non-judge, non-judge dimension of the Five Facets Mindfulness Questionnaire; FFMS non-react, non-react dimension of the Five Facets Mindfulness Questionnaire; Physical condition, having or not physical disability

\section{Associations Between Sexual and Relationship Satisfaction and Acceptance}

To assess the relationship between sexual satisfaction and acceptance, age was included in the first step of the analyses, which did not explain a significant amount of variance $\left(R^{2}=\right.$ $\left..009 ; F_{1,192}=1.818, p=.179 ; \Delta R^{2}=.009\right)$. The model was significant at step 2 , with the insertion of physical condition, which explained an additional $4.1 \%$ of the variance $\left(\Delta R^{2}=\right.$ $\left..041 ; R^{2}=.051 ; F_{1,191}=8.337, p=.004\right)$. With the inclusion of the total score of acceptance at step 3, the amount of added explained variance was $11.6 \%\left(\Delta R^{2}=.116 ; R^{2}=.166 ; F_{1,190}\right.$
$=26.335, p<.001)$. This result indicates that lower psychological inflexibility or experiential avoidance was associated with higher sexual satisfaction, above and beyond having a physical disability and after controlling for age $(\beta=0.366, p<$ .001) (see Table 5). Also, several hierarchical multiple regressions were conducted with the assistance of the PROCESS to test potential moderation effects of physical condition and gender. However, no moderating effects were found, as there were no significant interaction terms between physical condition and acceptance, and between gender and acceptance.

Finally, regarding the association between relationship satisfaction and acceptance, age was included in the first 
Table 4 Hierarchical linear regression analyses of selfcompassion dimensions as predictors of sexual $(n=167)$ and relationship satisfaction $(n=169)$ in the total sample $(N=377)$

\begin{tabular}{|c|c|c|c|c|c|c|}
\hline Variable & $B$ & SE $B$ & $\beta$ & $t$ & $R^{2}$ & $\Delta R^{2}$ \\
\hline \multicolumn{7}{|l|}{ GMSEX } \\
\hline Step 1 & & & & & .015 & .015 \\
\hline Age & 0.129 & 0.080 & 0.124 & 1.60 & & \\
\hline Step 2 & & & & & .062 & .047 \\
\hline Age & 0.035 & 0.085 & 0.034 & 0.416 & & \\
\hline Physical condition & -0.224 & 0.078 & -0.234 & $-2.86^{* *}$ & & \\
\hline Step 3 & & & & & .148 & .085 \\
\hline Age & 0.089 & 0.085 & 0.086 & 1.05 & & \\
\hline Physical condition & -0.206 & 0.078 & -0.215 & $-2.64 * *$ & & \\
\hline SCS self-kindness & 0.013 & 0.114 & 0.013 & 0.112 & & \\
\hline SCS self-judgment & -0.224 & 0.136 & -0.216 & -1.64 & & \\
\hline SCS common humanity & -0.082 & 0.109 & -0.081 & -0.752 & & \\
\hline SCS isolation & 0.049 & 0.117 & 0.050 & 0.422 & & \\
\hline SCS mindfulness & -0.054 & 0.120 & -0.053 & -0.451 & & \\
\hline SCS over-identification & -0.084 & 0.131 & -0.080 & -0.645 & & \\
\hline \multicolumn{7}{|l|}{ GMREL } \\
\hline Step 1 & & & & & .030 & .030 \\
\hline Age & 0.176 & 0.078 & 0.172 & $2.25 *$ & & \\
\hline Step 2 & & & & & .073 & .043 \\
\hline Age & 0.098 & 0.081 & 0.095 & 1.19 & & \\
\hline Physical condition & -0.212 & 0.076 & -0.222 & $-2.78 * *$ & & \\
\hline Step 3 & & & & & .174 & .101 \\
\hline Age & 0.141 & 0.080 & 0.138 & 1.75 & & \\
\hline Physical condition & -0.206 & 0.075 & -0.216 & $-2.75^{* *}$ & & \\
\hline SCS self-kindness & 0.116 & 0.114 & 0.119 & 1.01 & & \\
\hline SCS self-judgment & -0.159 & 0.132 & -0.155 & -1.20 & & \\
\hline SCS common humanity & -0.200 & 0.107 & -0.197 & -1.87 & & \\
\hline SCS isolation & 0.033 & 0.113 & 0.034 & 0.295 & & \\
\hline SCS mindfulness & -0.042 & 0.118 & -0.041 & -0.352 & & \\
\hline SCS over-identification & -0.145 & 0.129 & -0.139 & -1.12 & & \\
\hline
\end{tabular}

$* p<0.05 ; * * p<0.01 ; * * * p<0.001$

Final $n$ of the analyses range from 167 to 169 due to occasional missing data. All variables were computed into $z$ scores

GMSEX, total score Global Measure of Sexual Satisfaction; GMREL, total score of Global Measure of Relationship Satisfaction; FFMS observe, observe dimension of the Five Facets Mindfulness Questionnaire; FFMS describe, describe dimension of the Five Facets Mindfulness Questionnaire; FFMS act with awareness, act with awareness dimension of the Five Facets Mindfulness Questionnaire; FFMS non-judge, non-judge dimension of the Five Facets Mindfulness Questionnaire; FFMS non-react, non-react dimension of the Five Facets Mindfulness Questionnaire; Physical condition, having or not physical disability step of the hierarchical multiple regression, which explained $2.4 \%$ of the variance of relationship satisfaction $\left(R^{2}=.024 ; F_{1,194}=4.850, p=.029 ; \Delta R^{2}=.024\right)$. With the insertion of physical condition at step 2 , the added variable explained an additional $3.4 \%$ of the variance of the model $\left(\Delta R^{2}=.034 ; R^{2}=.058 ; F_{1,193}=\right.$ $6.939, p=.009)$. The inclusion of the total score of acceptance at step 3 explained an additional $10.6 \%$ of the variance $\left(\Delta R^{2}=.106 ; R^{2}=.165 ; F_{1,192}=24.425, p<\right.$ $.001)$. This result suggests that lower psychological inflexibility or experiential avoidance was associated with higher relationship satisfaction, independent from having a physical disability and after controlling for age $(\beta=$ $0.363, p<.001$ ) (see Table 5). Moreover, several hierarchical multiple regressions were conducted with the assistance of the PROCESS to test potential moderation effects of physical condition and gender. Nevertheless, no moderating effects were found for the interaction terms between physical condition and acceptance, or between gender and acceptance. 


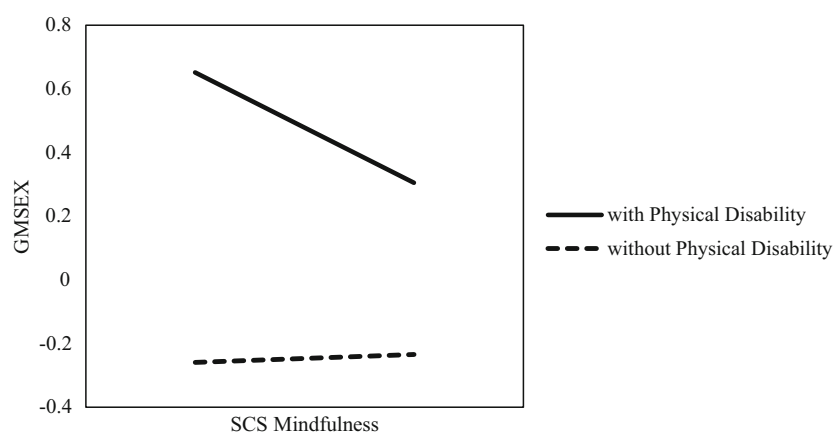

Fig. 1 Simple slopes for the moderation effect of physical condition on the relationship between sexual satisfaction and the mindfulness dimension of self-compassion $(N=377)$. Variables' scores are unstandardized

\section{Discussion}

Overall, findings showed that participants' higher levels of mindfulness, self-compassion, and acceptance were significantly associated with their higher sexual and relationship

Table 5 Hierarchical linear regression analyses of acceptance as predictor of sexual $(n=194)$ and relationship satisfaction $(n=196)$ in the total sample $(N=377)$

\begin{tabular}{|c|c|c|c|c|c|c|}
\hline Variable & $B$ & SE $B$ & $\beta$ & $t$ & $R^{2}$ & $\Delta R^{2}$ \\
\hline \multicolumn{7}{|l|}{ GMSEX } \\
\hline Step 1 & & & & & .009 & .009 \\
\hline Age & 0.095 & 0.071 & 0.097 & 1.34 & & \\
\hline Step 2 & & & & & .051 & .041 \\
\hline Age & 0.003 & 0.077 & 0.003 & 0.039 & & \\
\hline Physical condition & -0.214 & 0.074 & -0.224 & $-2.88 * *$ & & \\
\hline Step 3 & & & & & .166 & .116 \\
\hline Age & 0.046 & 0.072 & 0.047 & 0.636 & & \\
\hline Physical condition & -0.135 & 0.071 & -0.141 & -1.88 & & \\
\hline AAQ-II & 0.366 & 0.071 & 0.348 & $5.13^{* * *}$ & & \\
\hline \multicolumn{7}{|l|}{ GMREL } \\
\hline Step 1 & & & & & .024 & .024 \\
\hline Age & 0.155 & 0.071 & 0.156 & $2.20 *$ & & \\
\hline Step 2 & & & & & .058 & .034 \\
\hline Age & 0.079 & 0.075 & 0.079 & 1.04 & & \\
\hline Physical condition & -0.193 & 0.073 & -0.199 & $-2.63 * *$ & & \\
\hline Step 3 & & & & & .165 & .106 \\
\hline Age & 0.133 & 0.072 & 0.134 & $1.85^{*}$ & & \\
\hline Physical condition & -0.115 & 0.071 & -0.119 & -1.62 & & \\
\hline AAQ-II & 0.363 & 0.074 & 0.335 & $4.94 * * *$ & & \\
\hline
\end{tabular}

$* p<0.05 ; * * p<0.01 ; * * * p<0.001$

Final $n$ of the analyses range from 194 to 196 due to occasional missing data. All variables were computed into $z$-scores

GMSEX, total score Global Measure of Sexual Satisfaction; GMREL, total score of Global Measure of Relationship Satisfaction; AAQ-II, total score of Acceptance and Action Questionnaire (version 2); Physical condition, having or not physical disability satisfaction, regardless of the physical condition. Particularly, "act with awareness" facet of mindfulness was a significant predictor of sexual and relationship satisfaction, above and beyond physical condition. Moreover, findings showed a moderating effect of physical condition for the relationship between the mindfulness dimension of selfcompassion and sexual satisfaction.

As expected, higher levels of mindfulness, i.e., the capacity to be aware of the present moment, were associated with higher sexual and relationship satisfaction in people with and without physical disabilities. These findings are innovative by recognizing the potential link between mindfulness and sexual/relationship satisfaction in this population. Moreover, the results go in line with previous research documenting the health benefits of mindfulness in different samples of people with physical disabilities (Goodrich et al. 2015; Hocaloski et al. 2016; Senders et al. 2012). Particularly, in the present study, the facet "act with awareness" was negatively associated with sexual and relationship dissatisfaction, suggesting that, regardless of the physical condition, the ability to get involved in activities with full attention may contribute to the well-being with one's sexual and intimate life. Acting with awareness pertains not only to the external experience but also to the internal experience of one's thoughts and feelings (i.e., as things are happening in the present moment). This facet has been pointed out in previous studies as a predictor of sexual outcomes, namely sexual satisfaction (Leavitt et al. 2019). Being aware of one's sensations of pleasure and arousal seems particularly relevant to improve the subjective dimensions involved in sexual health. Thus, this result further highlights the influence of psychological factors, namely the kind of relationship that one establishes with thoughts and feelings, in adapting to sexual and intimate experiences, regardless of the circumstances (e.g., disability and/or sexual difficulties).

Regarding self-compassion, findings corroborated our hypotheses and showed that self-compassion significantly predicted sexual and relationship satisfaction in people with and without physical disabilities. Although none of the specific dimensions of the construct was significantly and independently associated with sexual and relationship satisfaction, overall, the capacity to be open to one's suffering with a kind and warm attitude was associated with a better subjective evaluation of one's sexual and intimate relationship. Previous evidence is scarce, but this result is consistent with the literature and emphasizes the potential role of selfcompassion as an aspect of resilience (Stuntzner et al. 2018; Stuntzner and Hartley 2015). In this study, the results suggest that a self-compassionate attitude towards one's arising thoughts and feelings is more likely to be associated with better sexual and relationship satisfaction, even in the face of a disabling condition. Additionally, a moderating effect of physical condition was observed for the relationship between 
the mindfulness dimension and sexual satisfaction, indicating that the negative correlation existed only for people with physical disabilities. Evidence is scarce, but this result is consistent with the existing literature on the potential role of selfcompassion as an important aspect of resilience in the face of disablism and/or sexual difficulties (Stuntzer 2014). The mindfulness dimension of self-compassion pertains to a balanced approach towards negative emotions so that these are neither suppressed nor exaggerated (Neff 2003b). Findings suggest that, particularly for people with disabilities, being able to hold in mindfulness awareness, any negative or unsuccessful events related to sexuality (i.e., observing thoughts and feelings as they are and putting them into a larger perspective) is more likely to be associated with better sexual satisfaction.

Lastly, findings showed that participants' levels of acceptance were significant predictors of sexual and relationship satisfaction of people with and without physical disabilities. This confirms the established hypotheses and is congruent with previous literature indicating the effectiveness of acceptance and commitment therapy in increasing sexual satisfaction in couples (Nezhad and Shameli 2017). These new findings suggest that, regardless of the physical condition, individuals with higher levels of acceptance may have lower experiential avoidance in the face of negative sexual events (e.g., negative thoughts and feelings towards sexual difficulties), which might contribute to their higher sexual and relationship satisfaction. According to Acceptance and Commitment Therapy, acceptance promotes psychological flexibility, which is interconnected with mindfulness skills of experiencing the present moment with active awareness (Pinto-Gouveia et al. 2012). Psychological flexibility may decrease experiential avoidance, promoting coping mechanisms that disentangle cognitive fusion with negative thoughts and feelings (Hayes 2004). Thus, this result further reinforces the subjective dimensions involved in sexual health and sheds light into psychological factors of sexual adjustment (Stuntzer 2014).

\section{Limitations and Future Research}

Our findings must be interpreted with caution due to some limitations of the study. Of most importance was the small number of participants and the use of a convenience sample, which may have compromised the representativeness of the data. The self-reported nature of the survey may have also added some bias to our results and compromise the assessment of physical condition. Nevertheless, the regression results indicate that, in the second steps, better physical condition (i.e., having no disability) was associated with higher sexual and relationship satisfaction, which is consistent with the literature and reassures the trust in our data (McCabe and Taleporos 2003; Taleporos and McCabe 2003). Likewise, in the first steps of the regression models, higher age was associated with worse sexual and relationship satisfaction, which is also consistent with the sociodemographic characteristics of the sample. Moreover, being a cross-sectional study also prevented the establishment of causal relationships between the variables. Finally, some effect sizes were very low (e.g., $R^{2}=.064$ to .153 ). This may indicate the influence of possible mediators that were not evaluated in this study (e.g., life satisfaction). For future research, replication of this study in a larger sample is much needed, also to allow the analysis of more complex structural equation models. Future studies should address these limitations and include other variables that may be confounding the results (e.g., sexual beliefs, sexual inhibition, body image, or self-esteem), as well as analyzing variables of sexual health such as sexual functioning. A longitudinal design could also be implemented to properly evaluate causal hypotheses.

Acknowledgments The authors would like to thank the Centro de Reabilitação Profissional de Gaia (Professional Rehabilitation Centre of Gaia) for the help in the recruitment procedures. We would also like to thank to all the institutions and associations that shared our study and helped us reach more participants. Finally, a special thank you to all the volunteers and their willingness in participating in the survey.

Author Contributions RP designed and executed the study, collected and analyzed the data, and wrote and revised the manuscript; IA collaborated in recruitment procedures, and collaborated in editing and reviewing the final manuscript; PT supervised the study design, collaborated in data analysis, and reviewed the final manuscript; PN supervised the study design, collaborated in data analysis and discussion of the findings, and reviewed the final manuscript. All authors approved the final version of the manuscript for submission.

Funding Information This work was funded by the Portuguese Scientific Foundation with a grant attributed to the first author (CPUP/FCT: UIDB/00050/2020; SFRH/BD/112168/2015).

Data Availability Due to the nature of this research (i.e., data containing sensitive information), participants did not agree for their data to be shared publicly, so raw data is not available. Supporting materials for data collection and analysis are available at the Open Science Framework at https://doi.org/10.17605/OSF.IO/ETJQP.

\section{Compliance with Ethical Standards}

Conflict of Interest The authors declare that they have no conflict of interest.

Ethical Approval All procedures involving human participants were in accordance with the ethical standards of the institutional research committee and with the 1964 Helsinki declaration and its later amendments or comparable ethical standards. Previous approval was obtained from the University Ethics Committee and from the Portuguese National Commission for Data Protection.

Informed Consent Informed consent was obtained from all the participants included in the study. 


\section{References}

Ahumuza, S., Matovu, J., Ddamulira, J., \& Muhanguzi, F. (2014). Challenges in accessing sexual and reproductive health services by people with physical disabilities in Kampala, Uganda. Reproductive Health, 11(1), 1-9. https://doi.org/10.1186/1742-4755-11-59.

Baer, R. (2003). Mindfulness training as a clinical intervention: a conceptual and empirical review. Clinical Psychology: Science and Practice, 10(2), 125-143. https://doi.org/10.1093/clipsy.bpg015.

Baer, R., Smith, G., Hopkins, J., Krietemeyer, J., \& Toney, L. (2006). Using self-report assessment methods to explore facets of mindfulness. Assessment, 13(1), 27-45. https://doi.org/10.1177/ 1073191105283504.

Bond, F., Hayes, S., Baer, R., Carpenter, K., Guenole, N., Orcutt, H., Waltz, T., \& Zettle, R. (2011). Preliminary psychometric properties of the Acceptance and Action Questionnaire-II: a revised measure of psychological inflexibility and experiential avoidance. Behavior Therapy, 42(4), 676-688. https://doi.org/10.1177/ 0748175614538064 .

Brotto, L., \& Heiman, J. (2007). Mindfulness in sex therapy: applications for women with sexual difficulties following gynecologic cancer. Sexual and Relationship Therapy, 22(1), 3-11. https://doi.org/10. 1080/14681990601153298.

Brotto, L., Basson, R., Smith, K., Driscoll, M., \& Sadownik, L. (2015). Mindfulness-based group therapy for women with provoked vestibulodynia. Mindfulness, 6(3), 417-432. https://doi.org/10. 1007/s12671-013-0273-z.

Brown, K., \& Ryan, R. (2003). The benefits of being present: mindfulness and its role in psychological well-being. Journal of Personality and Social Psychology, 84(4), 822-848. https://doi.org/10.1037/ 0022-3514.84.4.822.

Castilho, P., \& Pinto-Gouveia, J. (2011). Auto-compaixão: Estudo da validação da versão portuguesa da Escala da Auto-compaixão e da sua relação com as experiências adversas na infância, a comparação social e a psicopatologia. Psychologica, 54, 203-230.

Crewe, N., \& Krause, J. (1988). Marital relationships and spinal cord injury. Archives of Physical Medicine and Rehabilitation, 69(6), 435-438.

Dahm, K., Meyer, E., Neff, K., Kimbrel, N., Gulliver, S., \& Morissette, S. (2015). Mindfulness, self-compassion, posttraumatic stress disorder symptoms, and functional disability in U.S. Iraq and Afghanistan war veterans. Journal of Traumatic Stress, 28(5), 460-464. https:// doi.org/10.1002/jts.22045.

Esmail, S., Darry, K., Walter, A., \& Knupp, H. (2010). Attitudes and perceptions towards disability and sexuality. Disability and Rehabilitation, 32(14), 1148-1155. https://doi.org/10.3109/ 09638280903419277.

García, A., \& Álvarez, C. (2014). Sexuality and functional diversity: an analysis from a gender perspective. Procedia - Social and Behavioral Sciences, 161, 299-305. https://doi.org/10.1016/j. sbspro.2015.01.078.

Germer, C., \& Neff, K. (2013). Self-compassion in clinical practice. Journal of Clinical Psychology, 69(8), 856-867. https://doi.org/10. 1002/jclp.22021.

Goodrich, E., Wahbeh, H., Mooney, A., Miller, M., \& Oken, B. (2015). Teaching mindfulness meditation to adults with severe speech and physical impairments: an exploratory study. Neuropsychological Rehabilitation, 25(5), 708-732. https://doi.org/10.1080/09602011. 2014.970201

Gregório, S., \& Pinto-Gouveia, J. (2011). Facetas de mindfulness: características psicométricas de um instrumento de avaliação. Psychologica, 54, 259-280 https://doi.org/10.14195/1647-8606 54 10.

Hayes, $\overline{\text { S}}$. (2004). Acceptance and commitment therapy, relational frame theory, and the third wave of behavioral and cognitive therapies.
Behavior Therapy, 35(4), 639-665. https://doi.org/10.1016/S00057894(04)80013-3.

Hayes, A. (2012). PROCESS: a versatile computational tool for observed variable mediation, moderation, and conditional process modeling. https://www.semanticscholar.org/paper/PROCESS-\%3A-AVersatile-Computational-Tool-for-\%2C-\%2C-1-Hayes/ 862dd61cccad6b39ffe890557db19a6356bbe8ca

Hayes, S., Strosahl, K., \& Wilson, K. (1999). Acceptance and commitment therapy: an experiential approach to behavior change. New York: Guilford Press.

Hayter, M., \& Dorstyn, D. (2014). Resilience, self-esteem and selfcompassion in adults with spina bifida. Spinal Cord, 52(2), 167171. https://doi.org/10.1038/sc.2013.152.

Hocaloski, S., Elliott, S., Brotto, L., Breckon, E., \& McBride, K. (2016). A mindfulness psychoeducational group intervention targeting sexual adjustment for women with multiple sclerosis and spinal cord injury: a pilot study. Sexuality and Disability, 34(2), 183-198. https://doi.org/10.1007/s11195-016-9426-z.

Johnston, D. (2012). Mindfulness: A proposed couple-based intervention for the altered self-identity of breast cancer survivors. Mindfulness, 3(4), 282-290. https://doi.org/10.1007/s12671-012-0093-6.

Kabat-Zinn, J., \& Burney, R. (1981). The clinical use of awareness meditation in the self-regulation of chronic pain. Pain, 11, S273. https:// doi.org/10.1016/0304-3959(81)90541-8.

Kedde, H., van de Wiel, H., Schultz, W., Vanwesenbeeck, I., \& Bender, J. (2012). Sexual health problems and associated help-seeking behavior of people with physical disabilities and chronic diseases. Journal of Sex and Marital Therapy, 38(1), 63-78. https://doi.org/10.1080/ $0092623 X .2011 .569638$.

Kelland, M. D. (2009). Psicología, discapacidad física y la aplicación de la consciencia plena budista a los programas de artes marciales. Revista de Artes Marciales Asiáticas, 4(4), 8-17.

Kocsis, A., \& Newbury-Helps, J. (2016). Mindfulness in sex therapy and intimate relationships (MSIR): clinical protocol and theory development. Mindfulness, 7(3), 690-699. https://doi.org/10.1007/s12671016-0506-Z

Lawrance, K., \& Byers, S. (1992). Development of the interpersonal exchange model of sexual satisfaction in long term relationships. Canadian Journal of Human Sexuality, 1(3), 123-128.

Lawrance, K., \& Byers, S. (1995). Sexual satisfaction in long-term heterosexual relationships: the interpersonal exchange model of sexual satisfaction. Personal Relationships, 2(4), 267-285. https://doi.org/ 10.1111/j.1475-6811.1995.tb00092.x.

Leavitt, C. E., Lefkowitz, E. S., \& Waterman, E. A. (2019). The role of sexual mindfulness in sexual wellbeing, relational wellbeing, and self-esteem. Journal of Sex \& Marital Therapy, 45(6), 497-509. https://doi.org/10.1080/0092623X.2019.1572680.

Lucena-Santos, P., Pinto-Gouveia, J., \& Silva Oliveira, M. (2015). Terapias comportamentais de $3^{a}$ geração: Guia para profissionais. Synopsis Editora.

McCabe, M., \& Taleporos, G. (2003). Sexual esteem, sexual satisfaction, and sexual behavior among people with physical disability. Archives of Sexual Behavior, 32(4), 359-369.

McClelland, S. (2014). "What do you mean when you say that you are sexually satisfied?" A mixed methods study. Feminism \& Psychology, 24(1), 74-96. https://doi.org/10.1177/ 0959353513508392.

McCracken, L., \& Vowles, K. (2014). Acceptance and commitment therapy and mindfulness for chronic pain model, process, and progress. American Psychologist, 69(2), 178-187. https://doi.org/10.1037/ a0035623.

Mosalanejad, F., Afrasiabifar, A., \& Zoladl, M. (2018). Investigating the combined effect of pelvic floor muscle exercise and mindfulness on sexual function in women with multiple sclerosis: a randomized controlled trial. Clinical Rehabilitation, 32(10), 1340-1347. https://doi.org/10.1177/0269215518777877. 
Neff, K. (2003a). Self-compassion: an alternative conceptualization of a healthy attitude toward oneself. Self and Identity, 2(2), 85-101. https://doi.org/10.1080/15298860390129863.

Neff, K. (2003b). The development and validation of a scale to measure self-compassion. Self and Identity, 2(3), 223-250. https://doi.org/10. 1080/15298860390209035.

Neff, K., \& Dahm, K. (2015). Self-compassion: what it is, what it does, and how it relates to mindfulness. In B. O. M. Robinson \& B. Meier (Eds.), Handbook of mindfulness and self-regulation (pp. 121-140). Berlin: Springer.

Neff, K., \& Germer, C. (2013). A pilot study and randomized controlled trial of the mindful self-compassion program. Journal of Clinical Psychology, 69(1), 28-44. https://doi.org/10.1002/jclp.21923.

Nezhad, M., \& Shameli, L. (2017). The effect of acceptance and commitment therapy on sexual satisfaction of couples in Shiraz. International Journal of Medical Research \& Health Sciences, 6(1), 58-65.

Pascoal, P., Narciso, I., Pereira, N., \& Ferreira, A. (2013). Processo de validação da Global Measure of Sexual Satisfaction em três amostras da população portuguesa. Psicologia: Reflexão e Crítica, 26(4), 691-700. https://doi.org/10.1590/S010279722013000400009 .

Pascoal, P., Narciso, I., \& Pereira, N. (2014). What is sexual satisfaction? Thematic analysis of lay people's definitions. Journal of Sex Research, 51(1), 22-30. https://doi.org/10.1080/00224499.2013. 815149

Pascoal, P., Oliveira, L., \& Raposo, C. (2015). Evidências de validade da Global Measure of Relationship Satisfaction (GMREL) em três amostras da população portuguesa. Psicologia: Reflexão e Crítica, 28(1), 41-48. https://doi.org/10.1590/1678-7153.201528105.

Peixoto, M., \& Nobre, P. (2015a). Prevalence of sexual problems and associated distress among gay and heterosexual men. Sexual and Relationship Therapy, 30(2), 211-225. https://doi.org/10.1080/ 14681994.2014.986084.

Peixoto, M., \& Nobre, P. (2015b). Prevalence of sexual problems and associated distress among lesbian and heterosexual women. Journal of Sex \& Marital Therapy, 41(4), 427-439. https://doi.org/10.1080/ 0092623X.2014.918066.

Pinto-Gouveia, J., Gregório, S., Dinis, A., \& Xavier, A. (2012). Experiential avoidance in clinical and non-clinical samples: AAQII Portuguese version. International Journal of Psychology and Psychological Therapy, 12(2), 139-156.

Reeve, D. (2004). Psycho-emotional dimensions of disability and the social model. In C. Barnes \& G. M. (Eds.), Implementing the social model of disability: theory and research (pp. 83-100). Leeds: The Disability Press.

Rowen, T., Stein, S., \& Tepper, M. (2015). Sexual health care for people with physical disabilities. Journal of Sexual Medicine, 12(3), 584 589. https://doi.org/10.1111/jsm.12810.
Sánchez-fuentes, M., Santos-iglesias, P., \& Sierra, J. C. (2014). A systematic review of sexual satisfaction. International Journal of Clinical and Health Psychology, 14, 67-75. https://doi.org/10. 1016/S1697-2600(14)70038-9.

Senders, A., Wahbeh, H., Spain, R., \& Shinto, L. (2012). Mind-body medicine for multiple sclerosis: a systematic review. Autoimmune Diseases, 1(1), 1-12. https://doi.org/10.1155/2012/567324.

Shakespeare, T. (2006). Disability Rights and Wrongs. Abingdon: Routledge.

Smith, S. (2009). Social justice and disability: competing interpretations of the medical and social models. In K. Kristiansen, S. Vehmas, \& T. Shakespeare (Eds.), Arguing about disability: philosophical perspectives (pp. 15-29). Abingdon: Routledge.

Stuntzer, S. (2014). Self-compassion and sexuality: a new model for women with disabilities. Ideas and Research You Can Use: VISTAS 2014, 67(August).

Stuntzner, S., \& Hartley, M. (2015). Balancing self-compassion with selfadvocacy: a new approach for persons with disabilities. http://selfcompassion.org/wp-content/uploads/2015/08/Stuntzner_Hartley. pdf

Stuntzner, S., Dalton, J., \& Macdonald, A. (2018). The therapeutic triad of disability. https://ct.counseling.org/2018/07/the-therapeutictriad-of-disability/

Swain, J., \& French, S. (2008). Affirming identity. In J. Swain \& S. French (Eds.), Disability on equal terms (pp. 65-78). Thousand Oaks: SAGE Publications Ltd..

Taleporos, G., \& McCabe, M. (2003). Relationships, sexuality and adjustment among people with physical disability. Sexual and Relationship Therapy, 18(1), 25-43. https://doi.org/10.1080/ 1468199031000061245 .

World Health Organization. (2001a). International classification of functioning, disability and health. http://psychiatr.ru/download/1313? view $=$ name $=\mathrm{CF}$ 18.pdf

World Health Organization. (2001b). Disability Assessment Schedule 2.0 (WHODAS 2.0). World Health Organization. http://www.who.int/ classifications/icf/whodasii/en/

World Health Organization. (2006). Defining sexual health: report of technical consultation on sexual health 28-31 January 2002, Geneva. Sexual Health Document Series, (January), 0-30.

World Health Organization. (2011). What do we know about disability? World Health Organization. http://www.who.int/disabilities/world report/2011/report/en/

Publisher's Note Springer Nature remains neutral with regard to jurisdictional claims in published maps and institutional affiliations. 